\title{
Time course and relative dose potency of systemic effects from salmeterol and salbutamol in healthy subjects
}

\author{
Jon A Bennett, Anne E Tattersfield
}

\begin{abstract}
Background - The main adverse effects of $\beta_{2}$ agonists relate to their systemic activity. The time course and dose response relations of the systemic effects of salmeterol compared with salbutamol were investigated.

Methods - A double blind, randomised, crossover study was carried out in 14 healthy subjects who attended on seven days. Heart rate, $\mathbf{Q T}_{\mathrm{c}}$ interval, blood pressure, plasma potassium and glucose concentrations were measured for four hours following inhaled placebo, salmeterol 100, 200 and $400 \mu \mathrm{g}$ and salbutamol 600,1200 and $2400 \mu \mathrm{g}$ given by metered dose inhaler. Maximum changes from baseline and maximum absolute values following each dose of treatment were used to construct log dose response curves and calculate relative dose potency.
\end{abstract}

Results - Both salmeterol and salbutamol caused dose dependent changes in heart rate, $\mathbf{Q T}_{\mathrm{c}}$ interval, and plasma potassium and glucose concentrations. The onset of cardiac effects was rapid following both drugs, whereas changes in glucose and potassium concentrations occurred more gradually with salmeterol. The increase in heart rate and fall in potassium level were sustained over the four hours whereas glucose levels gradually returned towards baseline. The relative dose potency of salmeterol compared with salbutamol for changes from baseline was 7.1 (95\% CI 3.9 to 14.4$)$ for the $\mathrm{QT}_{\mathrm{c}}$ interval and $8.2(95 \%$ CI 5.7 to 12.6) for plasma potassium concentration. Salmeterol caused steeper dose response curves for heart rate and plasma glucose concentration than salbutamol so relative dose potency values could not be calculated.

Conclusions - These findings support previous data that salmeterol $100 \mu \mathrm{g}$ is broadly equivalent to salbutamol $800 \mu \mathrm{g}$ for systemic effects. The greater systemic effects of salmeterol are most likely to be due to greater potency relative to dose, although it may also have greater systemic bioavailability. The steeper dose response curve for heart rate with salmeterol indicates that it has a narrower therapeutic window than salbutamol and thus should be prescribed at the lowest effective dose. (Thorax 1997;52:458-464)

Keywords: salmeterol, salbutamol, systemic activity.
Beta $_{2}$ agonists have adverse systemic effects if administered in high doses. This may be relevant to the two most recent epidemics of asthma deaths since the $\beta$ agonists implicated - isoprenaline and fenoterol - were administered as high dose formulations compared with salbutamol and terbutaline, in addition to being less $\beta_{2}$ adrenoceptor selective. ${ }^{1-7}$ The long acting $\beta_{2}$ agonist salmeterol is more potent than salbutamol so the recommended dose for salmeterol is lower $(50 \mu \mathrm{g}$ compared with $200 \mu \mathrm{g}$ ), implying a fourfold potency difference. $^{8}$ The potency ratio of salmeterol to salbutamol may be greater, however, as potency ratios of 10-100 were found in studies in vitro and values of $8-10$ for systemic effects in subjects with asthma. ${ }^{9-11}$

Due to differences in the time course of salmeterol and salbutamol, a non-cumulative dose response protocol is a better way of comparing the systemic effects of the two drugs than the cumulative dose response studies carried out previously. ${ }^{1011}$ We have compared the time course and dose response relations of salmeterol and salbutamol in healthy, non-asthmatic subjects. Subjects inhaled single doses of salmeterol 100, 200 and $400 \mu \mathrm{g}$, salbutamol 600,1200 and $2400 \mu \mathrm{g}$, and placebo on separate days and the heart rate, blood pressure, $\mathrm{QT}_{\mathrm{c}}$ interval, plasma potassium and glucose concentrations were monitored for four hours after administration.

\section{Methods}

SUBJECTS

Fourteen subjects (seven men) aged between 20 and 45 years were recruited. All were within $15 \%$ of ideal body weight (Metropolitan Life Insurance) and healthy as determined from full medical history, physical examination, and laboratory screening tests. Exclusion criteria included a history of drug allergy, drug abuse, alcohol consumption of four or more units a day, smoking more than 10 cigarettes per day, any regular medication during the four weeks prior to the study, and inability to use a metered dose inhaler satisfactorily. Women of child bearing age were required to have adequate contraception and a negative pregnancy test.

Subjects gave informed written consent and the study was approved by the Nottingham City Hospital and the University of Nottingham Medical School ethics committees.

\section{MEASUREMENTS}

Subjects were semi-recumbent for all pharmacodynamic measurements. Heart rate and 
$\mathrm{QT}_{\mathrm{c}}$ interval (QT interval corrected for heart rate) were measured by 12-lead electrocardiography (ECG) (Marquette MAC II, Marquette Electronics Inc) programmed to calculate heart rate, $\mathrm{QT}_{\mathrm{c}}$ interval, and to detect a change in $T$ wave amplitude of $>1 \mathrm{~mm}$ from the mean of five successive R-R intervals. Pulse rate, systolic and diastolic blood pressure were measured using a semi-automated sphygmomanometer (Narco Scientific BP203NA) with a standard width cuff. Venous blood samples were analysed in batches at the end of the study for plasma potassium concentrations by flame photometry (Olympus AU5000, Olympus Optical Company Limited, Eastleigh, UK) and plasma glucose concentrations by hexokinase assay (Olympus AU800, Olympus Optical Company Limited, Eastleigh, UK) in the Department of Clinical Chemistry (City Hospital, Nottingham).

PROTOCOL

This was a double blind, placebo controlled, seven way, crossover study with treatment order determined by a random code. A full medical history, examination and laboratory screening tests were carried out on an initial screening visit and subjects had to show that they could use a metered dose inhaler correctly. They were asked to take no medication other than paracetamol for analgesia during the study period and to refrain from strenuous exercise or alcohol for 24 hours and from food, caffeinated beverages, and smoking from midnight prior to each visit. A drink of water was permitted on waking after which nothing was ingested until the end of the visit.

Subjects attended the department at the same time on seven mornings with a washout period of at least 72 hours between visits. An intravenous cannula (Butterfly 21G) was inserted into a forearm vein and kept patent with heparinised saline and an automated sphygmomanometer was placed on the opposite arm. Subjects were then attached to a 12-lead electrocardiogram. The ECG and blood pressure were recorded at five minute intervals until stable baseline values were attained, defined as three consecutive readings of heart rate and blood pressure within $10 \mathrm{bpm}$ and $10 \mathrm{mmHg}$, respectively. Blood was taken on two occasions before dosing for baseline plasma potassium and glucose assay.

Once baseline measurements were stable subjects inhaled either placebo, salmeterol $(100,200$ or $400 \mu \mathrm{g})$ or salbutamol $(600,1200$ or $2400 \mu \mathrm{g}$ ) from a combination of six placebo and active drug metered dose inhalers. A separate set of six inhalers was used for each subject and treatment period. The active inhalers contained $200 \mu \mathrm{g}$ salbutamol or $25 \mu \mathrm{g}$ salmeterol per actuation. Each dose consisted of 16 actuations given as one actuation every 20 seconds and with the active treatments given last so that dosing was completed at the same time before subsequent measurements. Inhalers were primed before use by shaking and dispelling four actuations into the air outside the investigation room. After actuating the inhaler at functional residual capacity subjects inhaled to vital capacity and held their breath for 10 seconds.

Timing was started immediately after the final inhalation and heart rate was measured at one minute intervals for the first 10 minutes. Blood pressure and the $\mathrm{QT}_{\mathrm{c}}$ interval were measured at two and five minutes and heart rate, $\mathrm{QT}_{\mathrm{c}}$ interval, blood pressure, plasma potassium and glucose concentrations were measured at $10,20,30,45,60,90,120,150,180,210$, and 240 minutes after dosing. Measurements were always made in the same order - ECG followed by blood pressure and blood sampling. Adverse events were assessed by asking subjects "How are you?" at 30, 60, 120, and 240 minutes after dosing.

The study was to be stopped and oral propranolol $10 \mathrm{mg}$ given if there were clinically important symptoms or if the heart rate rose above $140 \mathrm{bpm}$. With 14 subjects, the study had over $90 \%$ power to detect a difference of $7 \mathrm{bpm}$ between any pair of treatments.

\section{ANALYSIS OF DATA}

The maximum change from baseline and the maximum (minimum for plasma potassium concentration and diastolic blood pressure) absolute values following each dose of treatment were calculated for each measurement. For all measurements from 10 minutes after drug administration treatment comparisons were made by multifactorial analysis of variance using period, treatment, and subjects as dependent variables. Log dose response curves were plotted for each end point. The mean heart rate during the first nine minutes was compared between treatments by analysis of variance. Seven of 1274 plasma potassium values exceeded $7.0 \mathrm{mmol} / 1$, probably due to incorrect placing in a fluoride bottle; these values were considered to be errors and were excluded from the analysis prior to unblinding. Adverse events were compared by the Fisher exact probability test.

Table 1 Mean (SE) baseline values of heart rate (HR), $Q T_{c}$ interval, plasma potassium concentration, plasma glucose concentration, diastolic and systolic blood pressure on the seven study days

\begin{tabular}{|c|c|c|c|c|c|c|c|}
\hline \multirow[b]{3}{*}{ HR (bpm) } & \multirow[t]{2}{*}{ Placebo } & \multicolumn{3}{|l|}{ Salmeterol } & \multicolumn{3}{|l|}{ Salbutamol } \\
\hline & & $100 \mu g$ & $200 \mu g$ & $400 \mu g$ & $600 \mu g$ & $1200 \mu \mathrm{g}$ & $2400 \mu \mathrm{g}$ \\
\hline & $61.4 \quad(1.6)$ & $65.0 \quad(2.3)$ & 63.8 & $66.1 \quad(2.2)$ & $64.3(1.9)$ & 64.1 & $65.5 \quad(2.5)$ \\
\hline $\mathrm{QT}_{\mathrm{c}}$ interval (ms) & 408.7 (3.5) & $408.1 \quad(4.2)$ & 406.7 (3.8) & $413.4 \quad(4.2)$ & $410.0 \quad(3.0)$ & $410.1 \quad(5.1)$ & $412.6 \quad(2.4)$ \\
\hline$\left[\mathrm{K}^{+}\right](\mathrm{mmol} / \mathrm{l})$ & $3.79(0.05)$ & $3.81(0.04)$ & $3.79(0.04)$ & $3.85(0.05)$ & $3.81(0.05)$ & $3.84(0.06)$ & $3.78(0.05)$ \\
\hline [Glucose] $(\mathrm{mmol} / \mathrm{l})$ & $4.89(0.08)$ & $5.13(0.09)$ & $5.12(0.10)$ & $5.17(0.12)$ & $5.02(0.10)$ & $5.19(0.13)$ & $4.83(0.18)$ \\
\hline Diastolic BP $(\mathrm{mm} \mathrm{Hg})$ & $68.0(1.6)$ & $69.3(1.8)$ & $67.7(1.5)$ & $69.1(1.4)$ & $69.8(2.0)$ & $69.7(2.4)$ & $69.5(1.8)$ \\
\hline Systolic BP (mm Hg) & 112.0 & 112.4 & $110.4 \quad(1.3)$ & $113.9 \quad(1.9)$ & $111.6 \quad(2.2)$ & 114.3 & 114.8 \\
\hline
\end{tabular}




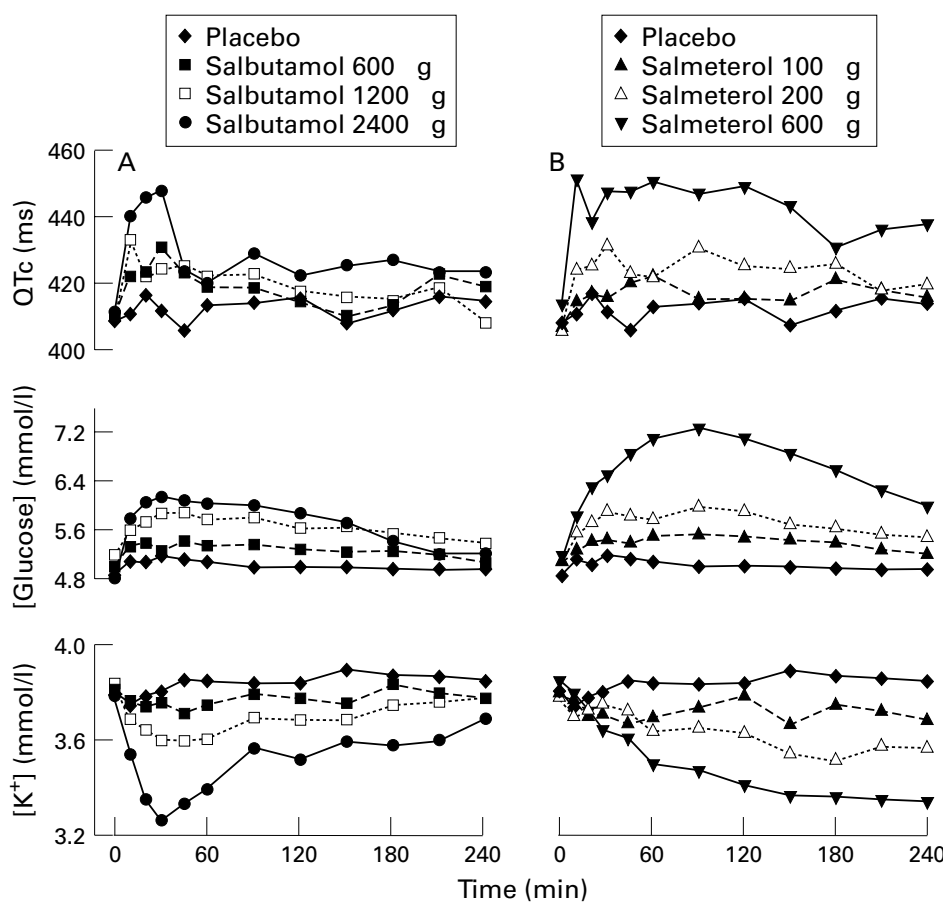

Figure 1 Mean values for $Q T_{c}$ interval, plasma potassium and glucose concentration over 240 minutes following placebo and $(A)$ salbutamol in doses of $600 \mu \mathrm{g}, 1200 \mu \mathrm{g}$ and $2400 \mu \mathrm{g}$ and $(B)$ salmeterol in doses of $100 \mu \mathrm{g}, 200 \mu \mathrm{g}$ and $400 \mu \mathrm{g}$.

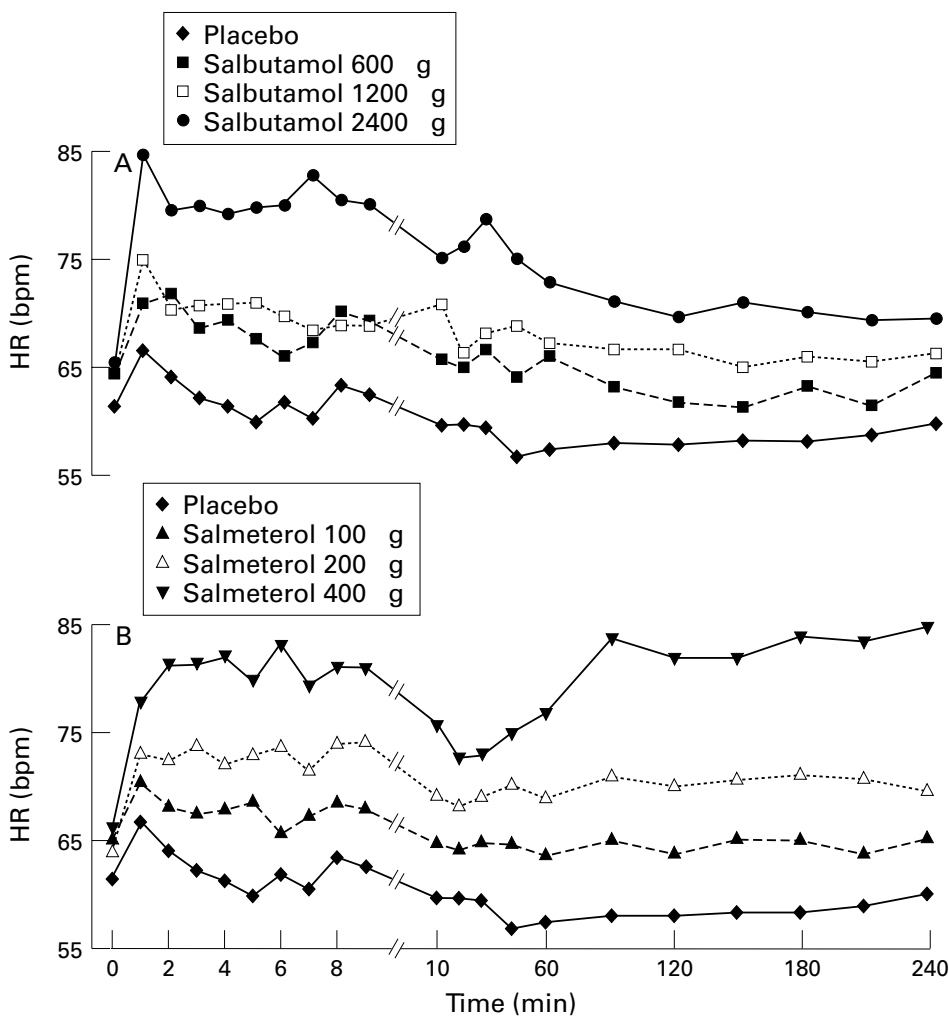

Figure 2 Mean values for heart rate over the first nine minutes and 10-240 minutes following placebo and (A) salbutamol in doses of $600 \mu \mathrm{g}, 1200 \mu \mathrm{g}$ and $2400 \mu \mathrm{g}$ and (B) salmeterol in doses of $100 \mu \mathrm{g}, 200 \mu \mathrm{g}$ and $400 \mu \mathrm{g}$.
Finney. ${ }^{12}$ If findings were not significant, an estimate of the relative dose potency of salmeterol compared with salbutamol was obtained with $95 \%$ confidence intervals (CI). If the curves were not parallel or not linear, salbutamol $600 \mu \mathrm{g}$ was compared with salmeterol $100 \mu \mathrm{g}$, salbutamol $1200 \mu \mathrm{g}$ with salmeterol $200 \mu \mathrm{g}$, and salbutamol $2400 \mu \mathrm{g}$ with salmeterol $400 \mu \mathrm{g}$ by paired $t$ test. Analyses were carried out using a SAS statistical package.

\section{Results}

All 14 subjects, mean age 29.7 years (range 20-45), completed the study. Ten subjects were lifelong non-smokers, two were ex-smokers (less than five pack years), and two were current smokers (less than 10 cigarettes per day). Baseline values showed no significant treatment effect (table 1).

\section{TIME COURSE}

$Q T_{c}$ interval, blood pressure, plasma potassium and glucose concentrations

Salbutamol and salmeterol caused a dose related increase in the $\mathrm{QT}_{c}$ interval and plasma glucose concentration and a fall in the plasma potassium concentration (fig 1). The increase in $\mathrm{QT}_{\mathrm{c}}$ interval was rapid following both drugs, although the increase was more prolonged with salmeterol. The fall in the plasma potassium concentration and the increase in the plasma glucose concentration following salmeterol occurred more gradually and were more prolonged than those seen following salbutamol; the greatest difference in time to maximum effect occurred with the highest dose of both drugs (fig 1). No dose related changes in systolic or diastolic blood pressure occurred with either drug.

\section{Heart rate}

Both drugs caused a dose related increase in heart rate one minute after inhalation which was sustained over the following nine minutes (fig 2). The maximum increase in heart rate occurred within 30-53 minutes for all doses of salbutamol and had largely disappeared by 240 minutes, whereas the maximum increase with salmeterol occurred between 75 and 135 minutes and values were still high at 240 minutes.

The highest dose of salmeterol $(400 \mu \mathrm{g})$ caused a greater mean (SE) increase in heart rate (33 (4.3) bpm) and plasma glucose concentration $(2.3(0.36) \mathrm{mmol} / \mathrm{l})$ than the highest dose of salbutamol $(2400 \mu \mathrm{g}, 24$ (1.5) bpm, and $1.6(1.57) \mathrm{mmol} / \mathrm{l})$. Salmeterol also produced the greatest individual changes in heart rate $(59 \mathrm{bpm})$, plasma potassium concentration $(-1.3 \mathrm{mmol} / \mathrm{l})$, plasma glucose concentration $(5.2 \mathrm{mmol} / \mathrm{l})$, and $\mathrm{QT}_{\mathrm{c}}$ interval $(199 \mathrm{~ms}) \mathrm{com}$ pared with salbutamol $(36 \mathrm{bpm},-1.1 \mathrm{mmol} / \mathrm{l}$, $3.5 \mathrm{mmol} / 1$, and $182 \mathrm{~ms}$, respectively).

Log dose response curves were tested for lack of linearity at the $5 \%$ level and for lack of parallelism at the $10 \%$ level over the dose range employed according to the methods of
RELATIVE DOSE POTENCY

The log dose response relationships for change and for absolute values of heart rate 


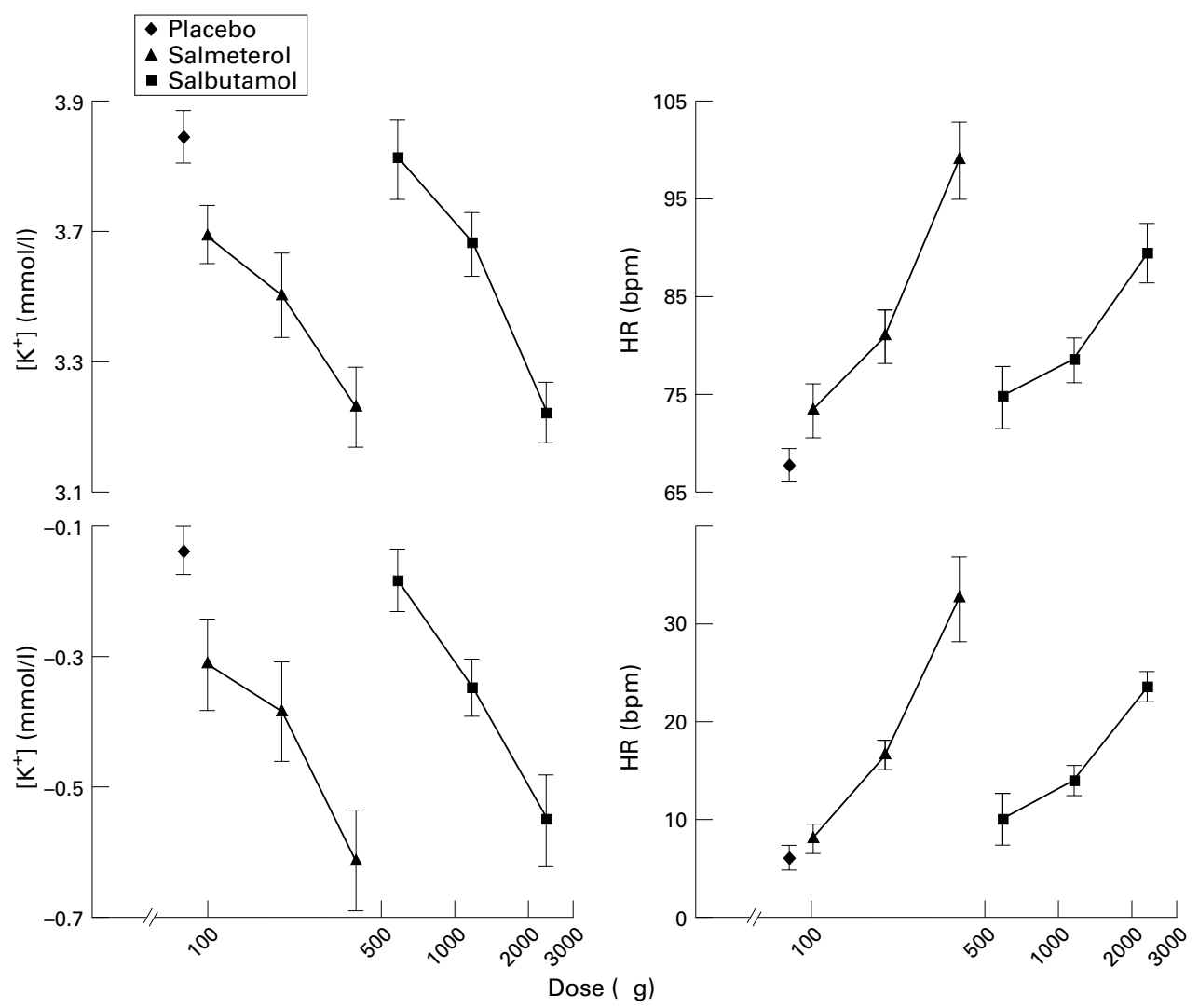

Figure 3 Mean (SE) maximum changes from baseline and absolute values for plasma potassium concentration and heart rate following placebo, salmeterol in doses of $100 \mu \mathrm{g}, 200 \mu \mathrm{g}$ and $400 \mu \mathrm{g}$, and salbutamol in doses of $600 \mu \mathrm{g}$, $1200 \mu \mathrm{g}$ and $2400 \mu \mathrm{g}$.

(10-240 min), $\mathrm{QT}_{\mathrm{c}}$ interval, and plasma potassium and glucose concentrations were linear $(\mathrm{p}>0.05)$ for both salmeterol and salbutamol except for absolute heart rate $(p=0.045)$ and plasma glucose concentration $(\mathrm{p}=0.019)$ following salmeterol. For the measurements which produced a linear log dose response following both drugs, $\mathrm{QT}_{\mathrm{c}}$ interval and plasma potassium concentration did not deviate from parallelism $(p>0.10)$ whilst changes in heart rate (10-240 min) and plasma glucose concentration were significantly non-parallel $(\mathrm{p}=$ 0.013 and $\mathrm{p}=0.018$, respectively), the response to salmeterol being steeper than that to salbutamol (figs 3 and 4).

The mean $(95 \% \mathrm{CI})$ relative dose potency for change and absolute values of plasma potassium concentration of salmeterol compared with salbutamol were 8.2 (5.7 to 12.6 ) and 7.8 (5.9 to 10.5), and for change and absolute values of $\mathrm{QT}_{\mathrm{c}}$ interval were 7.1 (3.9 to 14.4 ) and 6.5 (3.8 to 11.8 ).

For heart rate and plasma glucose concentration salmeterol $100 \mu \mathrm{g}$ and $200 \mu \mathrm{g}$ did not differ significantly from salbutamol $600 \mu \mathrm{g}$ and $1200 \mu \mathrm{g}$, respectively; however, salmeterol $400 \mu \mathrm{g}$ caused a significantly greater increase in both measurements than salbutamol $2400 \mu \mathrm{g}$ $(\mathrm{p}<0.01)$.

\section{ADVERSE EVENTS}

Symptoms

Adverse events (particularly tremor and palpitations) occurred significantly more often with salmeterol $400 \mu \mathrm{g}$ than with salmeterol $200 \mu \mathrm{g}$ or salbutamol $2400 \mu \mathrm{g}$. Salmeterol $200 \mu \mathrm{g}$ and salbutamol $2400 \mu \mathrm{g}$ caused more adverse effects than placebo. There were no significant differences in the frequency of adverse effects between placebo, salbutamol $600 \mu \mathrm{g}$ and $1200 \mu \mathrm{g}$, or salmeterol $100 \mu \mathrm{g}$.

\section{ECG changes}

Prolonged $\mathrm{QT}_{\mathrm{c}}$ interval, defined as $>460 \mathrm{~ms}$, and $T$ wave flattening occurred more commonly with the higher doses of $\beta_{2}$ agonists and with salmeterol more than with salbutamol. Other ECG changes included premature ventricular beats (one salbutamol $2400 \mu \mathrm{g}$ ) and first degree atrioventricular block (one placebo, one salmeterol $100 \mu \mathrm{g}$ ).

\section{Discussion}

Inhalation of salmeterol and salbutamol caused dose dependent changes in heart rate, $\mathrm{QT}_{\mathrm{c}}$ interval, and plasma glucose and potassium concentrations as expected from $\beta_{2}$ agonists.

\section{TIME COURSE}

The timing and magnitude of the changes in heart rate, $\mathrm{QT}_{\mathrm{c}}$ interval, plasma glucose and potassium concentrations following salbutamol were broadly similar to those seen in previous studies. ${ }^{101113}$ Inhaled salmeterol had a slower onset of action than salbutamol, although both drugs caused an early dose dependent increase 


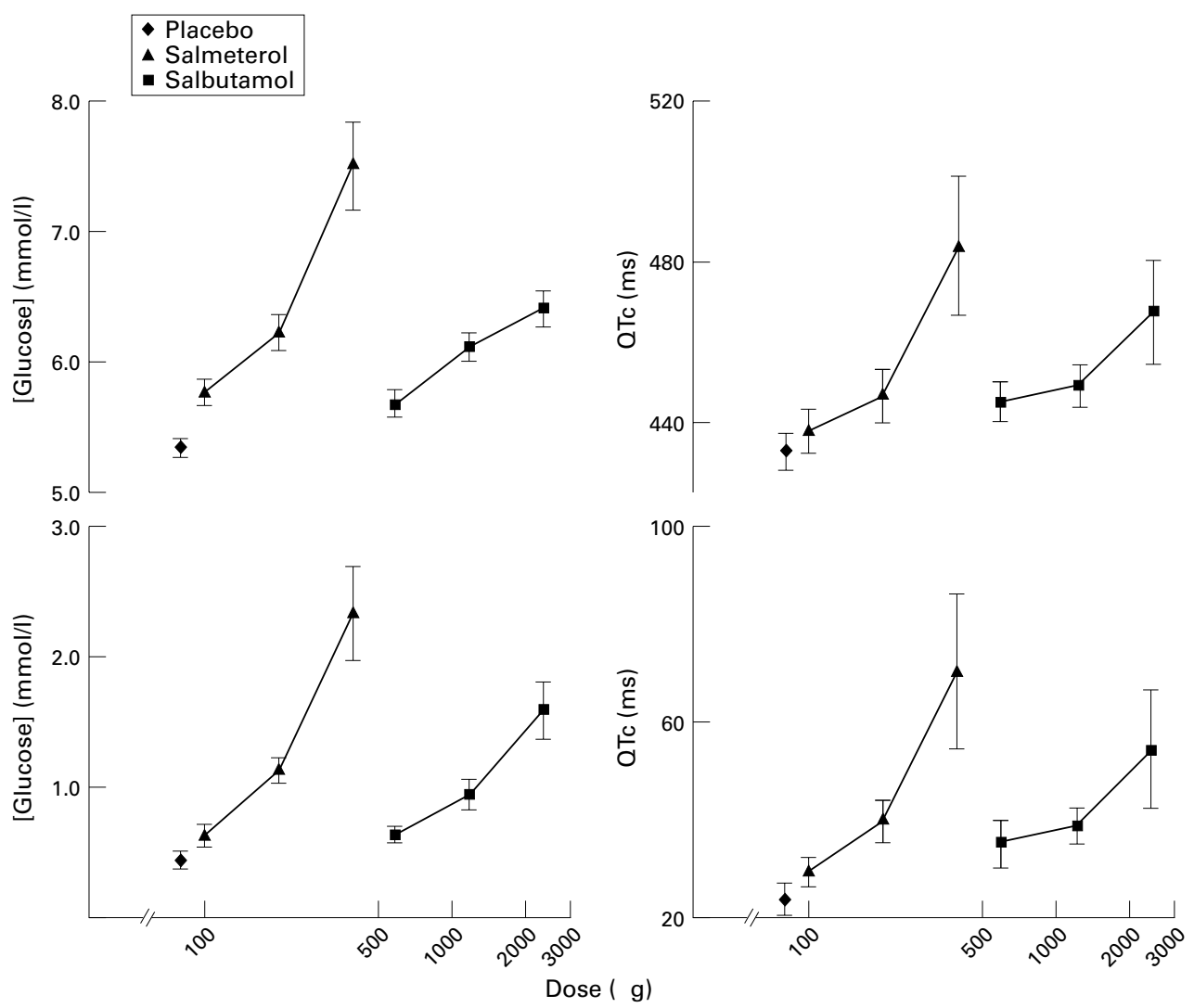

Figure 4 Mean (SE) maximum changes from baseline and absolute values for the plasma glucose concentration and $Q T_{c}$ interval following placebo, salmeterol in doses of $100 \mu \mathrm{g}, 200 \mu \mathrm{g}$ and $400 \mu \mathrm{g}$ and salbutamol in doses of $600 \mu \mathrm{g}$, $1200 \mu \mathrm{g}$ and $2400 \mu \mathrm{g}$.

in heart rate which was apparent after one minute and was sustained. The mean maximum increase in heart rate during the first 10 minutes when heart rate was recorded at one minute intervals was $19 \mathrm{bpm}$ for salbutamol (at one minute) and $17 \mathrm{bpm}$ for salmeterol (at six minutes). Such a rapid and large increase in heart rate has not been documented previously with either drug. The increase in $\mathrm{QT}_{\mathrm{c}}$ interval following both drugs was also rapid, whilst the changes in plasma potassium and glucose concentrations occurred more gradually. The rapid cardiac effects may therefore be due to a direct effect of the $\beta$ agonist on the heart following rapid absorption from the lung or, possibly, the buccal mucosa, analogous to the bolus effect seen with intravenous administration.

The early rise in heart rate with both $\beta_{2}$ agonists was followed by a further increase. This was particularly marked one to two hours after salmeterol $400 \mu \mathrm{g}$ and may in part be due to absorption of the swallowed fraction of inhaled salmeterol from the gastrointestinal tract. Both drugs were given by metered dose inhaler without a spacer so that some $80 \%$ of the drug is likely to have been swallowed. ${ }^{14}$ Peak plasma concentrations of salmeterol and salbutamol usually occur one hour after an oral dose (Glaxo Wellcome data on file). ${ }^{15}$

The plasma glucose concentration had returned towards baseline at four hours after salmeterol, presumably due to homeostatic re- sponses including insulin release and reduced glucagon production. In contrast, the increase in heart rate and the fall in the plasma potassium concentration were sustained at four hours whilst the $\mathrm{QT}_{\mathrm{c}}$ interval had fallen slightly. The absence of homeostasis for the $\beta_{2}$ agonist induced tachycardia is presumably because heart rate is predominantly controlled by sympathetic tone and any compensatory increase in vagal tone would have a small effect at most.

We found no significant changes in blood pressure following either drug, in keeping with some previous studies, ${ }^{61013}$ although others have shown a dose dependent increase in the systolic blood pressure or a decrease in the diastolic blood pressure. ${ }^{16-18}$ The differences between studies may reflect differences in the efficiency of homeostatic control of blood pressure or confounding by other factors that affect blood pressure.

RELATIVE DOSE POTENCY

The log dose response curves for $\mathrm{QT}_{\mathrm{c}}$ interval and plasma potassium concentration were linear and parallel whereas those for heart rate and plasma glucose concentration were steeper for salmeterol than for salbutamol. This meant that we could only calculate a relative dose potency for salmeterol compared with salbutamol for change in $\mathrm{QT}_{\mathrm{c}}$ interval and plasma potassium concentration; the figures we obtained, 7.1 and 8.2 , respectively, are similar 
to our previous estimates in man. ${ }^{1011}$ There was no significant difference in heart rate or glucose between the low and medium doses of the two $\beta_{2}$ agonists whereas salmeterol $400 \mu \mathrm{g}$ caused a significantly greater maximum chronotropic and hyperglycaemic response than salbutamol $2400 \mu \mathrm{g}$. The frequency of adverse effects showed a similar pattern with the lowest doses of salmeterol $(100 \mu \mathrm{g})$ and salbutamol $(600 \mu \mathrm{g})$ having a similar profile to placebo whilst the highest dose of salmeterol $(400 \mu \mathrm{g})$ had the most adverse effects, in keeping with its greater systemic effects and prolonged action.

\section{EXPLANATION OF OUR FINDINGS}

Salmeterol is approximately 10 times more potent than salbutamol in relaxing pre-contracted tracheal tissue and in inhibiting airway smooth muscle contraction, two $\beta_{2}$ adrenoceptor mediated effects. ${ }^{819}$ Our finding that salmeterol was some 7-8 times more potent than salbutamol in producing $\beta_{2}$ adrenoceptor mediated systemic effects (change in plasma potassium and $\mathrm{QT}_{\mathrm{c}}$ interval) is in keeping with these data. Another possible explanation for our potency difference is that salmeterol has greater systemic bioavailability due to increased absorption from the lung, buccal mucosa, or decreased gastrointestinal tract first pass metabolism. At therapeutic doses the swallowed fraction of salbutamol contributes relatively little to systemic effects due to its fairly high first pass metabolism; ${ }^{2021}$ the extent of first pass metabolism for salmeterol is unknown. Absorption from the lung is affected by the size and site of deposition of particles from an inhaler and a third possible explanation for our findings is that more drug was deposited per puff from the metered dose inhaler delivering salmeterol than that delivering salbutamol, resulting in greater absorption of salmeterol into the systemic circulation. ${ }^{22}$ On balance, however, it seems likely that the high relative dose potencies are due to true differences in potency rather than differences in systemic absorption, although we are currently assessing the contribution of salmeterol absorption from the gastrointestinal tract to systemic effects.

The steeper log dose response curves for heart rate and glucose with salmeterol compared with salbutamol was unexpected. Differences in intrinsic activity and selectivity at $\beta_{2}$ adrenoceptors should not produce nonparallel log dose response curves, nor can it be attributed to increased systemic bioavailability of salmeterol since the $\mathrm{QT}_{\mathrm{c}}$ interval and plasma potassium dose response curves were not affected. Differences in homeostatic responses to the drugs would be expected to have, if anything, a greater effect on the maximum response to salmeterol because of its slower onset, and underestimation of the peak salbutamol effect is unlikely as frequent measurements were made throughout the study. A non-linear increase in effect would be seen if salmeterol demonstrated zero or mixed zero first order metabolism, but there is no evidence to support this and it does not explain the parallel dose response curves seen with plasma potassium concentrations and
$\mathrm{QT}_{\mathrm{c}}$ interval. The most likely explanation is that the doses of salbutamol given were insufficient to reach the steep part of the dose response curves, although similar doses appeared to produce heart rate responses on the linear portion of the log dose response curve in previous studies. ${ }^{1011}$ Alternatively, the high lipophilicity of salmeterol may produce a high myocardial reservoir and thus a greater and more prolonged cardiac response. ${ }^{2324}$

In conclusion, salmeterol was some eight times more potent than salbutamol for change in $\mathrm{QT}_{\mathrm{c}}$ interval and plasma potassium concentration which suggests that, for peak systemic effects, salmeterol $100 \mu \mathrm{g}$ is broadly equivalent to salbutamol $800 \mu \mathrm{g}$. The changes seen following salmeterol $100 \mu \mathrm{g}$ were small compared with placebo which is in keeping with the low incidence of adverse effects seen in most clinical studies. The largest individual changes seen after the lowest doses of both drugs for heart rate, $\mathrm{QT}_{\mathrm{c}}$ interval, plasma potassium and glucose concentrations were $+20 \mathrm{bpm}, \quad+53 \mathrm{~ms}, \quad-0.8 \mathrm{mmol} / \mathrm{l}$ and $+1.3 \mathrm{mmol} / \mathrm{l}$, respectively, for salmeterol $100 \mu \mathrm{g}$ and $+31 \mathrm{bpm},+76 \mathrm{~ms},-0.5 \mathrm{mmol} / 1$ and $+1.2 \mathrm{mmol} / 1$ for salbutamol $600 \mu \mathrm{g}$. Our study was carried out in fit healthy young subjects and although most patients with asthma will demonstrate tachyphylaxis to the systemic effects of regular salmeterol, some older subjects with other risk factors for cardiovascular adverse effects may show larger changes with therapeutic doses of salmeterol. The relatively steep dose response curves for salmeterol show that it has a relatively small therapeutic window and support the current recommendations that salmeterol should be prescribed at the lowest effective dose and that a twice daily rather than "as required" dose regimen is appropriate.

The authors would like to thank Glaxo Wellcome, Greenford, UK who supported the study, in particular Choy Man for technical support and Oliver Keene and Jan McRae (Medical Statistics Department) for generating the random code and Statistics Department) for generath
assistance with statistical analysis.

1 Pearce N, Grainger J, Atkinson M, Crane J, Burgess C, Gilliag C. Case control study of prescribed fenoterol and 1990;45:170-5.

Grainger J, Woodman K, Pearce N, Crane J, Burgess C, Keane A, et al. Prescribed fenoterol and death from asthm in New Zealand, 1981-7: a further case control study. Thorax 1991;46:105-11

3 Crane J, Pearce N, Flatt A, Burgess C, Jackson R, Kwong $\mathrm{T}$, et al. Prescribed fenoterol and death from asthma in New Zealand, 1981-83: case-control study. Lancet 1989; i:917-22.

4 Stolley PD. Asthma mortality: why the United States was spared an epidemic of deaths due to asthma. Am Rev Respir Dis 1972;105:883-90.

5 Crane J, Burgess C, Beasley R. Cardiovascular and hypokalaemic effects of inhaled salbutamol, fenoterol and isoprenaline. Thorax 1989;44:136-40.

6 Wong CS, Pavord ID, Williams J, Britton JR, Tattersfield AE. Bronchodilator, cardiovascular, and hypokalaemic effects of fenoterol, salbutamol, and terbutaline in asthma. Lancet 1990;336:1396-9.

7 Burgess CD, Windom HH, Pearce N, Marshall S, Beasley R, Siebers RW. Lack of evidence for $\beta_{2}$ receptor selectivity: a study of metaproterenol, fenoterol, isoproterenol, and a study of metaproterenol, fenoterol, isoproterenol, and epinephrine in patic

8 Ball DI, Brittain RT, Coleman RA, Denyer LH, Jack D, Johnson $\mathrm{M}$, et al. Salmeterol, a novel, long-acting beta 2adrenoceptor agonist: characterization of pharmacological activity in vitro and in vivo. Br F Pharmacol 1991;104 665-71.

9 Roux FJ, Grandordy B, Douglas JS. Functional and binding characteristics of long acting $\beta_{2}$-agonists in lung and heart. Am $\mathcal{F}$ Respir Crit Care Med 1996;153:1489-95. 
10 Smyth ET, Pavord ID, Wong CS, Wisniewski AF, Williams $\mathrm{J}$, Tattersfield AE. Interaction and dose equivalence of salbutamol and salmeterol in patients with asthma. BMf 1993;306:543-45.

11 Bennett JA, Smyth ET, Pavord ID, Wilding PJ, Tattersfield AE. Systemic effects of salbutamol and salmeterol in patients with asthma. Thorax 1994;49:771-4.

12 Finney DJ. Statistical methods in biological assay. London: Griffin, 1964.

13 Maconochie JG, Forster JK. Dose-response study with highdose inhaled salmeterol in healthy subjects. $\mathrm{Br} \mathcal{f}$ Clin dose inhaled salmeterol ir

14 Davies DS. Pharmacokinetics of inhaled substances. Postgrad Med $\mathcal{f}$ 1975;51:69-75.

5 Morgan DJ. Clinical pharmacokinetics of beta-agonists. Clin Pharmacokinet 1990;18:270-94.

16 Lipworth BJ, Clark RA, Dhillon DP, Brown RA, McDevitt DG. Beta-adrenoceptor responses to high doses of inhaled salbutamol in patients with bronchial asthma. $\mathrm{Br} \mathcal{F}$ Clin Pharmacol 1988;26:527-33.

17 Newnham DM, Wheeldon NM, Lipworth BJ, McDevitt DG. Single dose comparison of the relative cardiac beta 1 beta $a_{2}$ activity of inhaled fenoterol in normal subjects. Thorax 1993;48:656-8.
18 Newnham DM, Lipworth BJ. Nebuliser performance, pharmacokinetics, airways and systemic effects of salbutamo given via a novel nebuliser delivery system ("Ventstream") Thorax 1994;49:762-70.

19 Dougall IG, Harper D, Jackson DM, Leff P. Estimation of the efficacy and affinity of the beta 2-adrenoceptor agonist salmeterol in guinea-pig trachea. Br F Pharmacol 1991; 104:1057-61.

20 Collier JG, Dobbs RJ, Williams I. Salbutamol aerosol causes a tachycardia due to the inhaled rather than the swallowed fraction. Br 7 Clin Pharmacol 1980;9:273-4.

21 Morgan DJ, Paull JD, Richmond BH, Wilson-Evered E Ziccone SP. Pharmacokinetics of intravenous and ora salbutamol and its sulphate conjugate. Br f Clin Pharmacol 1986;22:587-93.

22 Clark RA, Lipworth BJ. Lung bioavailability of chlorofluorocarbon free, dry powder and chlorofluorocarbon containing formulations of salbutamol. Brf Clin Pharmacol 1996;41:247-9.

23 Rhodes DG, Newton R, Butler R, Herbette L. Equilibrium and kinetic studies of the interactions of salmeterol with membrane bilayers. Mol Pharmacol 1992;42:596-602.

24 Anderson GP, Linden A, Rabe KF. Why are long-actin beta-adrenoceptor agonists long-acting? Eur Respirf 1994 ; 7:569-78. 